\title{
HOW WORD MEANING INFLUENCES WORD READING
}

Corresponding author:

Jo Taylor

Department of Psychology

Royal Holloway, University of London

Egham

Surrey

TW20 0EX

J.Taylor@rhul.ac.uk

Word count: 2622 
HOW WORD MEANING INFLUENCES WORD READING

\author{
J. S.H. Taylor ${ }^{1}$ \\ Fiona J. Duff ${ }^{2}$ \\ Anna M. Woollams ${ }^{3}$ \\ Padraic Monaghan ${ }^{4}$ \\ Jessie Ricketts ${ }^{1}$
}

${ }^{1}$ Department of Psychology, Royal Holloway, University of London

${ }^{2}$ Department of Experimental Psychology, University of Oxford

${ }^{3}$ School of Psychological Sciences, University of Manchester

${ }^{4}$ Department of Psychology, University of Lancaster 


\section{ABSTRACT}

Understanding how we read is a fundamental question for psychology, with critical implications for education. Studies of word reading tend to focus on the mappings between the written and spoken forms of words. In this paper, we review evidence from developmental, neuroimaging, neuropsychological, and computational studies that show that knowledge of word meanings is inextricably involved in word reading. Consequently, models of reading must better specify the role of meaning in skilled reading and its acquisition. Further, our review paves the way for educationally realistic research to confirm whether explicit teaching of oral vocabulary improves word reading.

Key words: reading, learning, orthography, phonology, semantics 


\section{HOW WORD MEANING INFLUENCES WORD READING}

Reading is fundamental to operating in modern society. For literate adults, reading is immediate, automatic, and efficient. Despite this, reading is not an innate capability but is parasitic upon an earlier acquired spoken language system that includes information about what words sound like (phonology) and what they mean (semantics). The ultimate goal of learning to read is to comprehend texts, for which knowledge of word meanings is essential. The ability to recognise and read aloud words (encompassed by the term word reading throughout this review) is a pre-requisite for reading comprehension. Research has focused on the orthography (print) to phonology connections that underpin word reading. However, the role of word meanings in word reading is less well understood and is thus the focus of this review. As suggested by Balota (1990), seminal findings from the adult behavioural literature now demonstrate that word reading efficiency is significantly influenced by semantic variables, over and above frequency and orthographic factors (Cortese $\&$ Schock, 2013). Building on this, we review recent evidence from a number of research traditions, which show conclusively that word reading in alphabetic languages is influenced by knowledge of semantics.

Cognitive models of reading all include orthographic, phonological, and semantic representations of words, as well as the mappings between them. In computational models based on a classical dual-route approach (Figure 1A; Coltheart, Rastle, Perry, Langdon, \& Ziegler, 2001; Perry, Ziegler, \& Zorzi, 2007), activation of a word's semantics is not necessary for recognising or reading it aloud. In contrast, the triangle modelling tradition (Figure 1B; Harm \& Seidenberg, 2004; Monaghan \& Ellis, 2010; Plaut, McClelland, Seidenberg, \& Patterson, 1996; Woollams, Lambon Ralph, Plaut, \& Patterson, 2007) posits that semantic 
information directly affects the learning and processing of mappings between the written and spoken forms of words. More specifically, it predicts that meaning particularly aids print-to-sound mapping when this process is difficult (as in words with exceptional spellings, or for poorer readers), and also that skilled reading involves increased reliance on direct print-to-meaning mappings. Despite these proposals, the nature of semantic representations and how they impact word reading has been relatively neglected in theoretical and experimental studies. Here we redress the balance by showing that semantic knowledge; a) influences reading acquisition, b) is activated rapidly during word reading, c) impacts on reading deficits seen after brain damage, and d) is crucial for simulating reading development.
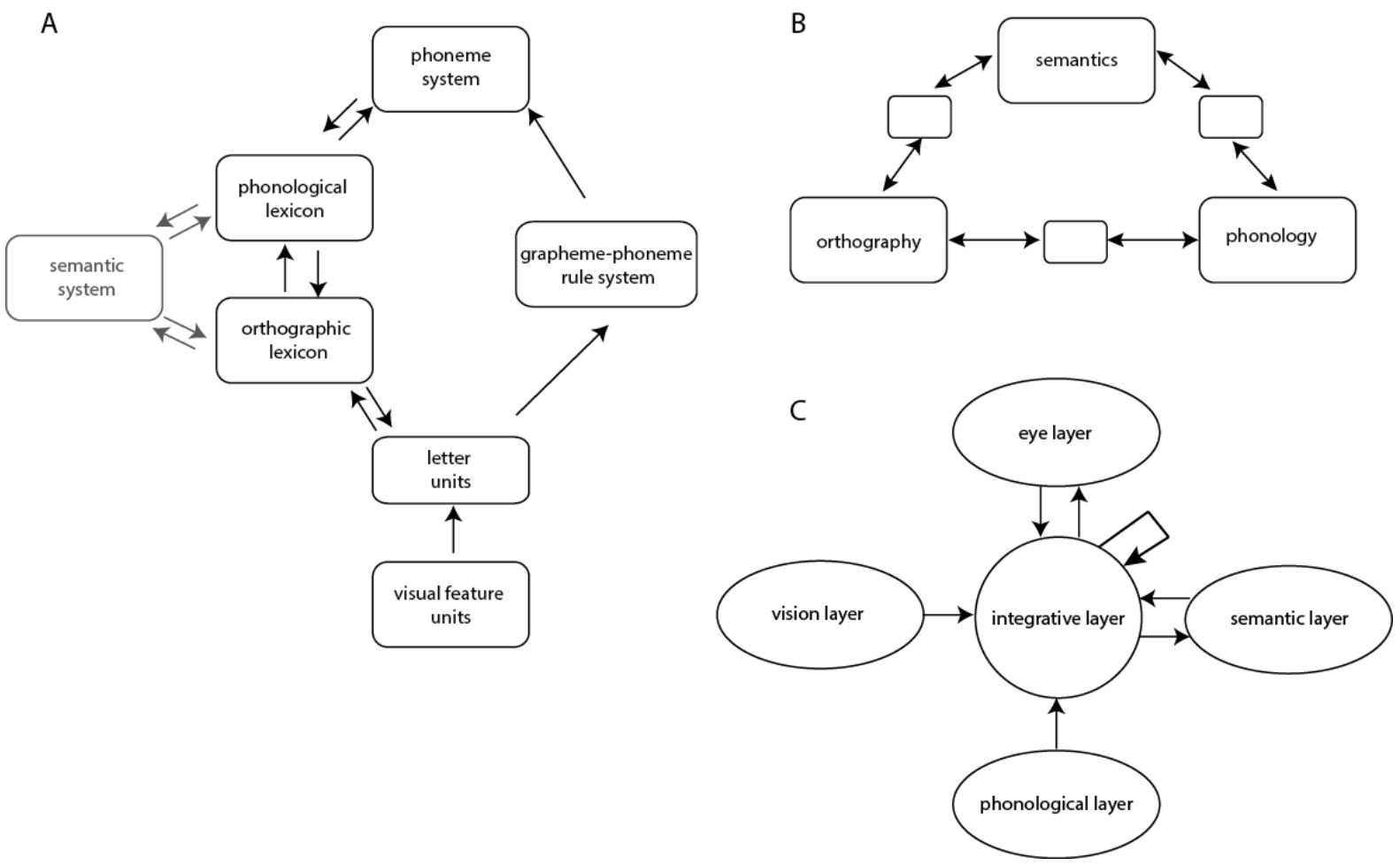

Figure 1. Computational models showing how semantics can influence word reading. A) Dual Route Cascaded model, in which the letters in a written word activate a whole-word 
orthographic lexical representation, and activation cascades both to whole-word phonological representations and to the semantic system. B) Triangle model, in which the letters in a written word activate phonological and semantic features via banks of hidden units. C) Central Resource model, in which orthographic, phonological, and semantic representations interact via a central resource (discussed further in Computational Modelling section). In the models depicted in B and C, semantic knowledge is rapidly activated so as to influence word reading, whereas, in the model depicted in A, semantic knowledge does not routinely influence word reading.

Developmental Psychology

Developmental research provides insights into the process of moving from effortful reading aloud to skilled silent reading. Furthermore, it can constrain hypotheses about the structure and function of the mature reading system, and inform our knowledge about how adults re-acquire reading after brain damage. Developmental psychology can address the critical question: What role does semantics have in learning to read words? Longitudinal studies show that children's oral vocabulary knowledge (an index of semantic knowledge) is associated with word reading later on in development, particularly for exception words such as touch, where the ou is not pronounced in the usual way (as in couch; Nation \& Snowling, 2004; Ricketts, Nation, \& Bishop, 2007).

Training studies help determine whether this relationship is causal, rather than merely correlational. Training studies exploring the effect of semantic knowledge on learning to read and spell have yielded mixed results. Duff and Hulme (2012; Study 1) taught 5- to 6-year-olds to read words that were in their oral, but not written, vocabulary (e.g., 
trouble). How well children could define the words (semantic knowledge) predicted how well they learnt to read aloud those same words. Duff and Hulme also showed that exposing children to the pronunciations of novel words (e.g., creth) before seeing them in print helped children learn to read the words. However, there was no additional benefit from preexposure to semantic information (see also McKague, Pratt, \& Johnston, 2001). In contrast, Wang, Nickels, Nation, and Castles (2013) found, using a similar paradigm, that 6- to 9-yearolds' ability to learn semantic information about novel words did predict later spelling of these words. The effect only held for exception words, a finding that has also been demonstrated in adults for reading aloud (Taylor, Plunkett, \& Nation, 2011). In summary, training studies suggest that a child or adult who already knows, or has just learnt, the meaning of a word will find it easier to learn that word's spelling-to-sound mapping, especially if this is exceptional.

There are a number of alternative (but not mutually exclusive) mechanistic accounts specifying how semantic knowledge might influence word reading. Oral vocabulary knowledge may help to resolve a partial decoding attempt (Share, 1995; Tunmer \& Chapman, 2012), or lead to better specified phonological representations (Metsala \& Walley, 1998), which in turn support word reading. Building on these ideas, theoretical frameworks, such as those depicted in Figure 1, must more fully account for the fact that reading does not develop in isolation, but latches onto an already developed spoken language system. Further, once reading instruction starts, spoken and written language develop in concert. Similarly, experimental paradigms must provide learning opportunities that are more akin to how children naturally build their spoken and written vocabularies. 
Also crucial will be systematic investigation of how the role of semantics changes as the demands of word reading evolve and as children's cognitive capacities develop.

Neuroimaging

Neuroimaging studies allow us to determine: Are brain areas involved in semantic processing active during word reading? The evidence shows that they are, even during tasks that do not require meaning to be accessed, such as reading aloud/silently and lexical decision (judging whether a letter string is a word). Relative to reading pseudowords (pronounceable but meaningless letter strings), reading words activates brain regions such as left angular and middle temporal gyri, which are likely involved in semantic processing (Taylor, Rastle, \& Davis, 2013; Taylor et al., 2014a). Furthermore, neurophysiological experiments reveal that this differential response to meaningful versus meaningless items can occur as early as $160-200$ ms post-stimulus onset (Carreiras, Armstrong, Perea, \& Frost, 2014). Thus, neuroimaging methods suggest that skilled readers activate semantic information rapidly and perhaps obligatorily during word reading.

In both a meta-analysis and an empirical study, Taylor et al. $(2013 ; 2014 a)$ found that exception words activate left inferior frontal gyrus more than regular words. This may reflect the retrieval and selection of semantic knowledge (Graves, Desai, Humphries, Seidenberg, \& Binder 2010), or selection between the multiple pronunciations that are possible for exception words (Taylor et al., 2013; 2014a). These proposals echo perspectives from the developmental literature in indicating that oral vocabulary knowledge may help to resolve a partial pronunciation of a written word (Tunmer \& Chapman, 2012). Evidence that semantic knowledge contributes to exception word reading comes also from Wilson et al. 
(2012) who found higher activation for exception words than pseudowords in the left anterior temporal lobe, an area associated with semantic processing (Visser, Jefferies, \& Lambon Ralph, 2010). Note that this finding is not consistently reported (Taylor et al., 2013), perhaps because the anterior temporal lobes are difficult to image using conventional methods (Visser et al., 2010).

Neuroimaging can also offer a window into the mechanisms underlying semantic involvement in reading. For example, Kherif, Josse, and Price (2010) used repetition suppression to show that pre-exposure to semantically related pictures reduced left fusiform activation to written words. This suggests that activation of a word's meaning aids processing of its written form. Another promising new method is multi-voxel pattern analysis, which can reveal the nature of the information represented in particular brain regions (for a relevant example see Nestor, Behrmann, \& Plaut, 2013). Finally, if combined with artificial language learning paradigms, neuroimaging methods could reveal how teaching meanings for novel words influences subsequent neural responses to their written forms (Taylor et al., 2011; Taylor, Rastle, \& Davis, 2014b).

Neuropsychology

Studying the performance of people with reading problems caused by brain damage (acquired dyslexia) provides a unique insight into which brain regions and associated cognitive functions are necessary for normal reading. A key question for neuropsychology is: What happens to reading when we lose knowledge of meaning? To answer this, we can consider reading aloud in patients with semantic dementia, who have a progressive and 
selective deterioration of multimodal semantic memory due to atrophy of the anterior temporal lobes (Adlam et al., 2006; Patterson, Nestor, \& Rogers, 2007).

Semantic dementia patients show striking difficulty reading aloud exception words, particularly when these words are low in frequency (e.g., scarce; Patterson \& Hodges, 1992), in line with activation of the left anterior temporal lobe for exception words in normal readers (Wilson et al., 2012). This reading deficit is not due to the malfunction of basic orthographic or phonological processing, as many semantic dementia patients read pseudowords, like karce, accurately (Woollams, Lambon Ralph, Plaut, \& Patterson, 2007), and their errors to exception words are usually phonologically plausible regularisations (i.e., scarce read to rhyme with farce). This reading profile is known as acquired surface dyslexia. Semantic dementia patients show a similar deficit when making lexical decisions about words with atypical spellings, such as yacht (Rogers, Lambon Ralph, Hodges, \& Patterson, 2004).

Semantic dementia patients are more likely to correctly read an exception word aloud if they still know the meaning of that word (Graham, Hodges, \& Patterson, 1994), mirroring results in the developmental literature (Ricketts et al., 2007). Large scale studies of semantic dementia have shown a strong link between the degree of the exception word reading deficit and the severity of semantic impairment on tasks that do not require reading (e.g., picture naming, spoken word-to-picture matching; Woollams et al., 2007). The remaining variation in exception word reading between patients with similar levels of semantic impairment may be determined by how much they relied on word meaning for reading before they experienced brain damage (Woollams et al., 2007). Future research 
should seek to understand the nature of such individual differences amongst normal readers at the behavioural and neural level.

We can also ask of neuropsychological data: What happens to reading when we lose knowledge of written or spoken word forms? Pure alexic patients have damage to the left ventral occipito-temporal region associated with orthographic processing in normal readers, making them very slow and particularly poor at reading long words. Phonological dyslexic patients have damage to the left perisylvian region that supports phonological processing in normal readers, and this makes them particularly poor at reading novel letter strings. Both types of patient show a strong influence of the imageability of a word's meaning on reading: they are more accurate reading words like chair than hope (Crisp, Howard, \& Lambon Ralph, 2011; Roberts, Lambon Ralph, \& Woollams, 2010). Hence it seems that word meaning can partially offset the consequences of damage to orthographic or phonological processing for reading; future research can explore the extent to which this could be harnessed to improve performance.

Computational Modelling

Computational models of reading allow us to ask: which theory of reading provides the best account of how semantics influences skilled reading, its development, and its breakdown in cases of reading disorder? Furthermore, they are useful in ensuring that the mechanisms necessary to account for an observed behaviour are made explicit. The triangle model (Figure 1B) suggests that semantics has an essential rather than peripheral, role in reading words. More recently, focus has turned to exploring how learning to read is 
influenced by the nature of the mappings between the spellings, sounds, and meanings of words.

Sound-to-meaning mappings for words are largely arbitrary (e.g., cat and cap sound similar but have distinct meanings). Computational modelling has shown that acquiring these mappings, as pre-literate children do when building their oral vocabulary, is resourceintensive (Lambon Ralph \& Ehsan, 2006). However, learning to map written to spoken forms is more systematic (e.g., cat and cap are similar orthographically and phonologically) and requires fewer resources. Paradoxically, modelling work finds that these systematic mappings, though easier to acquire, are less robustly represented and more prone to interference and change (Monaghan, Christiansen, \& Fitneva, 2011), whereas early-acquired arbitrary mappings exert an enduring influence on later learning. Hence, computational models make a clear prediction that pre-literate understanding of spoken word meanings affects later literacy development. These predicted effects are observed behaviourally in the greater influence of semantics for early acquired than late acquired words in reading speed (Davies, Wilson, Cuetos, \& Burani, 2014; Monaghan \& Ellis, 2010).

The triangle model maps written to spoken words via two pathways: one directly and the other indirectly via semantics. However, an alternative conception of the role of semantics is that it interacts with written and spoken forms via a central resource, as shown in Figure 1C (Dilkina, McClelland, \& Plaut, 2008; Smith, Monaghan, \& Huettig, 2013). Central resource models propose that semantics begins to be activated as quickly as the phonological form of a word and affects its visual identification (both for regular and exception words), echoing neuroimaging findings (e.g., Hauk et al., 2012). Furthermore, these models show that when we become literate, spoken words are more readily 
decomposed into their constituent sounds, but their meanings also continue to exert a strong influence on language processing (Smith, Monaghan, \& Huettig, 2014). This is because the arbitrary mappings between written and spoken forms and their meanings and are more robust and adjust less as a consequence of newly acquired information than written-to-spoken mappings.

Computational models of reading help us to understand why semantics is an integral contributor to word reading. However, they remain underspecified as to whether semantics provides a parallel pathway from orthography to phonology, or interacts with written and spoken forms via a central resource. Furthermore, computational models of reading development have not proceeded at the same pace as behavioural research; simulating the relative contribution of semantics at different stages of reading acquisition is imperative for a full understanding of how reading is acquired.

\section{CONCLUSION}

This review demonstrates the importance of integrating evidence from various methodological approaches in order to fully understand word reading. In summarising key recent developments, this review has been somewhat anglocentric. Future research should examine more fully the role of semantics in word reading in languages with more regular (e.g., Spanish, c.f. Davies, Barbón, \& Cuetos, 2013) and exceptional (e.g., Chinese, c.f. Williams \& Bever, 2010) orthography-phonology mappings. Nonetheless, we have shown conclusively that semantic knowledge is implicated in word reading. This insight provides constraints upon, and predictions for, future theorising. For example, modelling approaches (dual-route, triangle, central resource; see Figure 1) must be able to explain the effect of semantics on word reading across item types and individuals and provide more naturalistic 
accounts of learning. Furthermore, the reviewed findings have the potential to influence teaching practice. There is clear evidence that phonics-based instruction (with a focus on print-to-sound mappings) is highly effective in the teaching of early reading (McArthur et al., 2012). Going beyond this, our review of the evidence from multiple research traditions leads us to propose that learners who possess knowledge of the semantics of words will fare better when they come to the task of learning to read them. Practically, this suggests that explicit teaching of oral vocabulary (sound-to-meaning mappings) should precede and accompany phonics instruction. This proposal needs to be rigorously tested in educationally realistic studies. 


\section{ACKNOWLEDGEMENTS}

This review was inspired by presentations given at a workshop in September 2013, which was held at, and funded by, Newnham College, University of Cambridge. The workshop was organised by J. S. H. Taylor, Fiona J. Duff, and Jessie Ricketts, who made an equal contribution to leading this review. We would like to thank Kate Nation and Nicky Dawson for their helpful comments on an earlier draft of this manuscript.

J. S. H. Taylor was supported by a research fellowship from Newnham College, University of Cambridge.

Fiona J. Duff is supported by the Nuffield Foundation (grant number EDU/40062).

Anna M. Woollams is supported by the Economic and Social Research Council (UK) (grant number RES-062-23-3062) and the Rosetrees Trust (grant number A445).

Padraic Monaghan is supported by the Economic and Social Research Council (UK) (grant number ES/L008955/1).

Jessie Ricketts is supported by the Economic and Social Research Council (UK) grant number ES/K008064/1). 


\section{NOTES}

${ }^{1}$ Address correspondence to: Jo Taylor, Department of Psychology, Royal Holloway, University of London, Egham, Surrey, TW20 0EX. J.Taylor@rhul.ac.uk 


\section{REFERENCES}

Adlam, A. L. R., Patterson, K., Rogers, T. T., Nestor, P. J., Salmond, C. H., Acosta-Cabronero, J., \& Hodges, J. R. (2006). Semantic dementia and fluent primary progressive aphasia: Two sides of the same coin? Brain, 129, 3066-3080. doi: 10.1093/brain/awl285

Balota, D. A. (1990). The role of meaning in word recognition. In D. A. Balota, G. F. D'Arcais \& K. Rayner (Eds.), Comprehension Processes in Reading (pp. 9-32). Hillsdale, N. J.: Lawrence Erlbaum Associates.

Carreiras, M., Armstrong, B. C., Perea, M., \& Frost, R. (2014). The what, when, where, and how of visual word recognition. Trends in Cognitive Sciences, 18(2), 90-98.

Coltheart, M., Rastle, K., Perry, C., Langdon, R., \& Ziegler, J. (2001). DRC: A dual route cascaded model of visual word recognition and reading aloud. Psychological Review, 108(1), 204-256. doi: 10.1037/0033-295X.108.1.204

Cortese, M. J. \& Schock, J. (2013) Imageability and age of acquisition effects in disyllabic word recognition. Quarterly Journal of Experimnetal Psychology, 66(5), 946-972. doi: $10.1080 / 17470218.2012 .722660$

Crisp, J., Howard, D., \& Lambon Ralph, M.A. (2011). More evidence for a continuum between phonological and deep dyslexia: Novel data from three measures of direct orthography-to-phonology translation. Aphasiology, 25(5), 615-641. doi: $10.1080 / 02687038.2010 .541470$

Davies, R., Barbón, A., \& Cuetos, F. (2013). Lexical and semantic age-of-acquisition effects on word naming in Spanish. Memory and Cognition, 41(2), 297-311. doi: $10.3758 / \mathrm{s} 13421-012-0263-8$ 
Dilkina, K., McClelland, J. L., \& Plaut, D. C. (2008). A single-system account of semantic and lexical deficits in five semantic dementia patients. Cognitive Neuropsychology, 25(2), 136-164. doi: 10.1080/02643290701723948

Duff, F. J., \& Hulme, C. (2012). The role of children's phonological and semantic knowledge in learning to read words. Scientific Studies of Reading, 16(6), 504-525. doi: 10.1080/10888438.2011.598199.

Graham, K. S., Hodges, J. R., \& Patterson, K. (1994). The relationship between comprehension and oral reading in progressive fluent aphasia. Neuropsychologia, 32, 299-316. doi: 10.1016/0028-3932(94)90133-3

Graves, W. W., Desai, R., Humphries, C., Seidenberg, M. S., \& Binder, J. R. (2010). Neural systems for reading aloud: A multiparametric approach. Cerebral Cortex, 20, 17991815. doi: $10.1093 /$ cercor/bhp245

Harm, M., \& Seidenberg, M. S. (2004). Computing the meanings of words in reading: Cooperative division of labor between visual and phonological processes. Psychological Review, 111(3), 662-720. doi: 10.1037/0033-295X.111.3.662

Kherif, F., Josse, G., \& Price, C. J. (2010). Automatic Top-Down Processing Explains Common Left Occipito-Temporal Responses to Visual Words and Objects. Cerebral Cortex, 21, 103-114. doi: 10.1093/cercor/bhq063

Lambon Ralph, M. A., \& Ehsan, S. (2006). Age of acquisition effects depend on the mapping between representations and the frequency of occurrence: Empirical and computational evidence. Visual Cognition, 13(7-8), 928-948. doi: $10.1080 / 13506280544000110$ 
McKague, M., Pratt, C., \& Johnston, M. B. (2001). The effect of oral vocabulary on reading visually novel words: A comparison of the dual-route-cascaded and triangle frameworks. Cognition, 80, 231-262. doi: 10.1016/S0010-0277(00)00150-5

Metsala, J. L., \& Walley, A. C. (1998). Spoken vocabulary growth and the segmental restructuring of lexical representations: Precursors to phonemic awareness and early reading ability. In J. L. Metsala \& L. C. Ehri (Eds.), Word recognition in beginning literacy (pp. 89-120). Mahwah, NJ, US: Lawrence Erlbaum Associates.

Monaghan, P., \& Ellis, A. W. (2010). Modeling reading development: Cumulative, incremental learning in a computational model of word naming. Journal of Memory and Language, 63(4), 506-525. doi: 10.1016/j.jml.2010.08.003

Monaghan, P., Christiansen, M. H., \& Fitneva, S. A. (2011). The arbitrariness of the sign: Learning advantages from the structure of the vocabulary. Journal of Experimental Psychology: General, 140(3), 325-347. doi: 10.1037/a0022924

Nation, K., \& Snowling, M. J. (2004). Beyond phonological skills: Broader language skills contribute to the development of reading. Journal of Research in Reading, 27, 342356. doi: 10.1111/j.1467-9817.2004.00238.x

Nestor, A., Behrmann, M., \& Plaut, D. C. (2013). The neural basis of visual word form processing: A multivariate investigation. Cerebral Cortex, 23(7), 1673-1684. doi: 10.1093/cercor/bhs158

Patterson, K., \& Hodges, J. R. (1992). Deterioration of word meaning: Implications for reading. Neuropsychologia, 30, 1025-1040. doi: 10.1016/0028-3932(92)90096-5

Patterson, K., Nestor, P. J., \& Rogers, T. T. (2007). Where do you know what you know? The representation of semantic knowledge in the human brain. Nature Reviews Neuroscience, 8, 976-987. 
Perry, C., Ziegler, J. C., \& Zorzi, M. (2007). Nested incremental modeling in the development of computational theories: The CDP+ model of reading aloud. Psychological Review, 114(2), 273-315. doi: 10.1037/0033-295X.114.2.273

Plaut, D. C., McClelland, J. L., Seidenberg, M., \& Patterson, K. (1996). Understanding normal and impaired word reading: Computational principles in quasi-regular domains. Psychological Review, 103, 56-115. doi: 10.1037/0033-295X.103.1.56

Ricketts, J., Nation, K., \& Bishop, D. V. M. (2007). Vocabulary is important for some, but not all reading skills. Scientific Studies of Reading, 11(3), 235-257. doi:

$10.1080 / 10888430701344306$

Roberts, D.J., Lambon Ralph, M.A., \& Woollams, A.M. (2010). When does less yield more? The impact of severity upon implicit recognition in pure alexia. Neuropsychologia, 48, 2437-2446. doi: 10.1016/j.neuropsychologia.2010.04.002

Rogers, T. T., Lambon Ralph, M. A., Hodges, J. R., \& Patterson, K. (2004). Natural Selection: The impact of semantic impairment on lexical and object decision. Cognitive Neuropsychology, 21(2), 331-352.

Share, D. L. (1995). Phonological recoding and self-teaching: Sine qua non of reading acquisition. Cognition, 55, 151-218. doi: 10.1016/0010-0277(94)00645-2

Smith, A.C., Monaghan, P., \& Huettig, F. (2013). An amodal shared resource model of language-mediated visual attention. Frontiers in Language Sciences, 4, 00528. doi: 10.3389/fpsyg.2013.00528

Smith, A.C., Monaghan, P., \& Huettig, F. (2014). Literacy effects on language and vision: Emergent effects from an amodal shared resource (ASR) computational model. Cognitive Psychology, 75, 28-54. doi: 10.1016/j.cogpsych.2014.07.002 
Taylor, J. S. H., Plunkett, K., \& Nation, K. (2011). The influence of consistency, frequency, and semantics on learning to read: An artificial orthography paradigm. Journal of Experimental Psychology: Learning Memory and Cognition, 37(1), 60-76. doi: $10.1037 / a 0020126$

Taylor, J. S. H., Rastle, K., \& Davis, M. H. (2013). Can cognitive models explain brain activation during word and pseudoword reading? A meta-analysis of 36 neuroimaging studies. Psychological Bulletin, 139(4), 766-791. doi:

$10.1037 / a 0030266$

Taylor, J. S. H., Rastle, K., \& Davis, M. H. (2014a). Interpreting response time effects in functional imaging studies. Neuroimage, 99, 419-433. doi: 10.1016/j.neuroimage.2014.05.073

Taylor, J. S. H., Rastle, K., \& Davis, M. H. (2014b). Distinct neural specializations for learning to read words and name objects. Journal of Cognitive Neuroscience, 26(9), 21282154. doi: 10.1162/jocn_a_00614

Tunmer, W. E., \& Chapman, J. W. (2012). Does set for variability mediate the influence of vocabulary knowledge on the development of word recognition skills? Scientific Studies of Reading, 16(2), 122-140. doi: 10.1080/10888438.2010.542527

Visser, M., Jefferies, E., \& Lambon Ralph, M. A. (2010). Semantic processing in the anterior temporal lobes: a meta-analysis of the functional neuroimaging literature. Journal of Cognitive Neuroscience, 22(6), 1083-1094. doi: 10.1162/jocn.2009.21309

Wang, H. C., Nickels, L., Nation, K., \& Castles, A. (2013). Predictors of orthographic learning of regular and irregular words. Scientific Studies of Reading, 17(5), 369-384. doi: $10.1080 / 10888438.2012 .749879$ 
Williams, C. \& Bever, T. (2010). Chinese character decoding: A semantic bias? Reading and Writing, 23(5), 589-605. doi: 10.1007/s11145-010-9228-0

Wilson, M. A., Joubert, S., Ferré, P., Belleville, S., Ansaldo, A. I., Joanette, Y., . . Brambati, S. M. (2012). The role of the left anterior temporal lobe in exception word reading: Reconciling patient and neuroimaging findings. Neurolmage, 60(4), 2000-2007. doi: 10.1016/j.neuroimage.2012.02.009

Woollams, A. M., Lambon Ralph, M. A., Plaut, D. C., \& Patterson, K. (2007). SD-squared: On the association between semantic dementia and surface dyslexia. Psychological Review, 114, 316-339. doi: 10.1037/a0017641

Number of references: 40 
WORD MEANING AND READING / 23

\section{RECOMMENDED READING}

This paper discusses the role of meaning in reading development using connectionist models as a framework, and suggests directions for future modelling and empirical research. Nation, K. (2009). Form-meaning links in the development of visual word recognition. Philosophical Transactions of the Royal Society B: Biological Sciences, 364(1536), 3665-3674. doi: 10.1098/rstb.2009.0119

This paper proposes that visual word recognition is aided by top-down contributions from brain regions involved in processing linguistic information, such as phonology and semantics.

Price, C. J., \& Devlin, J. T. (2011). The Interactive account of ventral occipitotemporal contributions to reading. Trends in Cognitive Sciences, 15(6), 246-253. doi: 10.1016/j.tics.2011.04.001

This paper presents an overview of recent research concerning acquired dyslexia, with an emphasis on how visual, semantic, and phonological processing abilities support reading. Woollams, A. M. (2014). Connectionist neuropsychology: uncovering ultimate causes of acquired dyslexia. Philosophical Transactions of the Royal Society B: Biological Sciences, 369(1634). doi: 10.1098/rstb.2012.0398

An accessible review of alternative approaches to computational models of reading. 
Seidenberg, M. S. (2012). Computational models of reading: Connectionist and dual-route approaches. In M. Spivey., K. McRae., \& M. Joanisse. (Eds.), Cambridge Handbook of Psycholinguistics (pp. 186-203). Cambridge University Press.

This paper provides recent insights into the role of meaning in word recognition in adults Pexman, P. (2012). Meaning-based influences on visual word recognition. In J.S. Adelman (Ed.) Visual Word Recognition Volume 2 (pp. 24-43). Hove: Psychology Press. 


\section{FIGURE CAPTIONS}

Figure 1. Computational models showing how semantics can influence word reading. A) Dual Route Cascaded model, in which the letters in a written word activate a whole-word orthographic lexical representation, and activation cascades both to whole-word phonological representations and to the semantic system. B) Triangle model, in which the letters in a written word activate phonological and semantic features via banks of hidden units. C) Central Resource model, in which orthographic, phonological, and semantic representations interact via a central resource (discussed further in Computational Modelling section). In the models depicted in B and C semantic knowledge is rapidly activated so as to influence word reading, whereas, in the model depicted in A, semantic knowledge does not routinely influence word reading. 